\title{
Comminuted Radial Head Fracture in All-arthroscopic Repair of Elbow Fracture-dislocation: Is Partial Excision of the Radial Head an Acceptable Treatment Option?
}

\author{
Hee Seok Yang, Jeong Woo Kim ${ }^{凶}$, Sung Hyun Lee, Byung Min Yoo \\ Department of Orthopaedic Surgery, Wonkwang University Hospital, Iksan, Korea
}

Background: In elbow fracture-dislocation, partial excision of the comminuted radial head fracture that is not amenable to fixation remains controversial considering the accompanying symptoms. This study was undertaken to evaluate the results of radial head partial excision when the comminuted radial head fracture involved $<50 \%$ of the articular surface in all-arthroscopic repair of elbow fracturedislocation.

Methods: Patients were divided into two groups based on the condition of the radial head fracture. In Group A, the patients had a radial head comminuted fracture involving $<50 \%$ of the articular surface, and underwent arthroscopic partial excision. Group B was the nonexcision group comprising patients with stable and non-displacement fractures. Follow-up consultations were conducted at 6 weeks and at 3, 6, 12, and 24 months after surgery.

Results: In all, 19 patients (Group A: 11; Group B: 8) met the inclusion criteria and were enrolled in the study. At the final follow-up, all 19 patients showed complete resolution of elbow instability. No significant differences were observed in the range of motion, visual analogue scale score, and Mayo elbow performance score between groups. Radiological findings did not show any complications of the radiocapitellar joint. However, nonunion of the coracoid fracture was observed in 3 patients (Group A: 1; Group B: 2), without any accompanying instability and clinical symptoms.

Conclusions: Considering that the final outcome is coronoid fracture fixation and lateral collateral ligament complex repair for restoring elbow stability, arthroscopic partial excision for radial head comminuted fractures involving $<50 \%$ of articular surface is an effective and acceptable treatment for elbow fracture-dislocation.

(Clin Shoulder Elbow 2018;21(4):234-239)

Key Words: Elbow; Arthroscopy; Radial head

\section{Introduction}

Radial head fracture, the most common site of elbow fractures in adults, is associated with a $5 \%$ to $10 \%$ incidence of elbow dislocations, and reportedly requires anterior and lateral bony stabilization. ${ }^{1)}$ Most radial head fractures with dislocation are caused by a shearing force between the radial head and the humeral capitellum, resulting in the fracture (type IV of modified Mason classification) of the anterior part of the radial head or the entire joint surface. ${ }^{2)}$ The standard management of this injury is still under debate, and options for treatment include nonsurgical management, open reduction internal fixation (ORIF), excision, and radial head replacement. Factors influencing the decision making include the number and position of fracture fragments, the degree of displacement, and involvement of the articular surface. ${ }^{3-5)}$ Further, the state of any accompanying fracture and collateral ligament injury around the elbow also needs to be considered.

\footnotetext{
Received September 7, 2018. Revised October 11, 2018. Accepted October 11, 2018.

Correspondence to: Jeong Woo Kim

Department of Orthopaedic Surgery, Wonkwang University Hospital, 895 Muwang-ro, Iksan 54538, Korea

Tel: +82-63-859-1360, Fax: +82-63-852-9329, E-mail: serina@wonkwang.ac.kr, ORCID: https://orcid.org/0000-0002-0828-7179

IRB approval: Wonkwang University Hospital (WKUH 2018-01-011).

Financial support: None. Conflict of interests: None.
} 
Elbow fracture-dislocations involve a greater difficulty in managing radial head fractures. ${ }^{6}$ Although restoring the fractured radial head with comminution is the ideal option, ${ }^{7,8)}$ the unfortunate severity of comminution makes reconstruction difficult in several cases encompassing these fractures. Therefore, although some authors consider radial head excision as a viable treatment option and have reported good results, ${ }^{9,10)}$ excision of the radial head remains controversial with respect to its indications, methods, and excision range.

In this study, we attempted arthroscopic radial head partial excision in cases with severe comminuted fractures with $<50 \%$ of the articular surface involved, and where restoration was not possible. We aimed to evaluate and compare the outcomes of radial head partial excision and uninjured radial heads in all-arthroscopic treatment of elbow fracture-dislocation. We hypothesized that when a comminuted radial head fracture involves $<50 \%$ of the articular surface, arthroscopic radial head partial excision, accompanied by coronoid fracture fixation and lateral collateral ligament (LCL) complex repair for restoring elbow stability, presents satisfactory clinical outcomes with low complica- tion rates.

\section{Methods}

\section{Patient Selection}

We performed a retrospective review of consecutive patients who had presented with elbow fracture-dislocation between 2011 and 2016. The inclusion criteria were: (i) elbow fracturedislocation with instability after manual reduction (positive drop sign, elbow stability not maintained on flexion of $<30^{\circ}$, and positive lateral posterolateral pivot-shift test finding); (ii) treatment with all-arthroscopic surgery; and (iii) clinical assessment of a minimum of 18 months postoperative follow-up. The exclusion criteria were as follows: (i) ORIF of a fracture of the radial head, if not amenable to arthroscopic management; (ii) radial head replacement; (iii) radial neck fracture; (iv) coronoid process fracture involving the medial facet or unable to be reduced with arthroscopy (such fractures are treated with open surgery); and (v) history of injury or surgery of the elbow. All patients were divided into two groups, based on the condition of the radial head
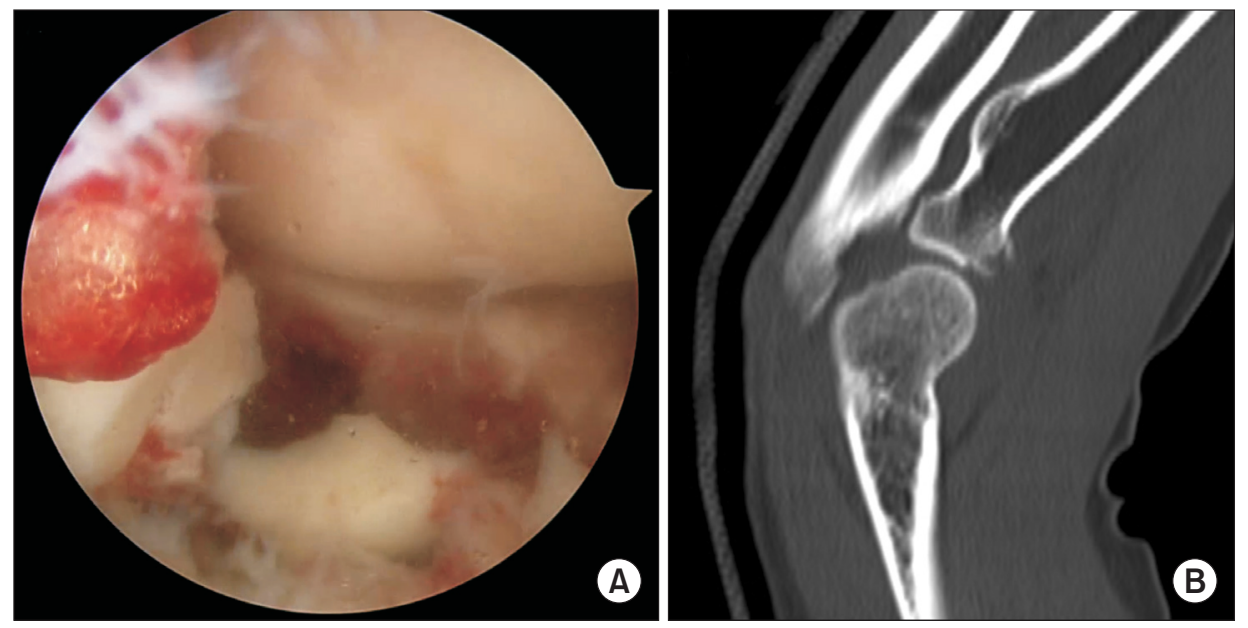

Fig. 1. Arthroscopic findings (A) and preoperative three-dimensional computed tomography image (B) of comminuted radial head fracture.
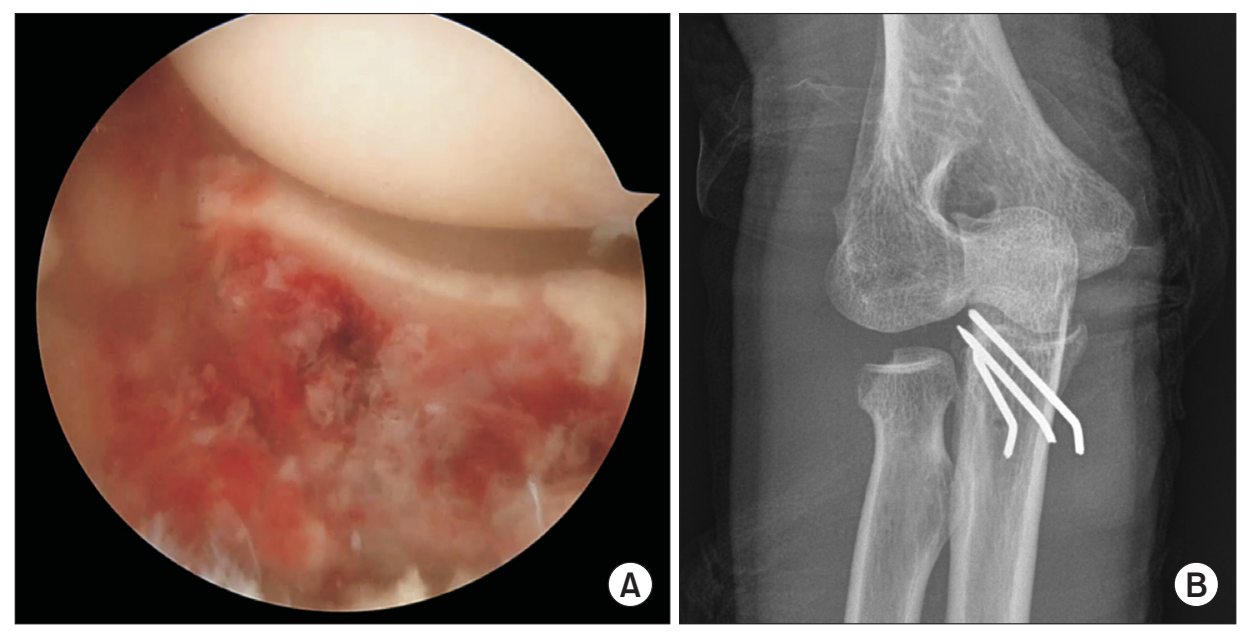

Fig. 2. Arthroscopic view (A) and anteroposterior radiography (B) of radial head fracture after excision of fracture fragment. 
fracture. Each group underwent arthroscopic partial excision for a non-reconstructable, comminuted fracture, involving $<50 \%$ of the articular surface (Group A), and non-excision for stable and non-displacement fractures or no-fractures (Group B).

\section{Surgical Procedure \& Postoperative Management}

All surgeries were performed by a senior surgeon, within a week subsequent to the trauma. A 10-ml dose of normal saline was injected through the lateral soft spot to increase the joint space, and the degree of joint damage was confirmed by arthroscopy through the proximal anteromedial portal. The management of the radial head fracture was decided based on the preoperative three-dimensional computed tomography images and intraoperative findings (Fig. 1). Considering that a probe is used to execute the arthroscopic reduction of a radial head fracture, a displaced fracture that cannot be reduced was treated with arthroscopic fracture fragment excision (Fig. 2). In case of a stable radial head fracture with displacement of the articular surface less than $2 \mathrm{~mm}$, the fracture was treated conservatively.

Further, all cases presenting with combined coronoid fractures (or anterior capsular avulsion) and LCL complex injuries were treated using the arthroscopic technique for restoring elbow stability. Coronoid fractures with fracture fragments sufficiently large for penetration were fixed using a Kirschner wire. Typically, 2 or 3 unthreaded Kirschner wires were used for fixation of the coronoid fracture. Reduction was achieved using Kirschner wires inserted from the posterior to the anterior aspect of the ulna. The smaller coronoid fractures were fixed via suture repair. Reduction was performed arthroscopically by suturing the surrounding anterior capsule of the coronoid. For the LCL complex repair, a spinal needle was inserted through the radial head portal to penetrate the LCL complex stump. A polydioxanone (PDS; Ethicon, Somerville, NJ, USA) suture was passed through the spinal needle, and the shuttle relay was performed by connecting the PDS with a FiberWire. The sequence was repeated with a 10-mm gap left between the current and the previous stitches. An anterolateral portal was created using a spinal needle, and the FiberWire (Arthrex, Munich, Germany) was then transferred from the radial head portal to this portal for fixation at the $\mathrm{LCL}$ complex footprint. The FiberWires were fixed using one knotless

Table 1. Data of the Patients Who Underwent Arthroscopic Treatment for Radial Head Fracture with Elbow Fracture-dislocation

\begin{tabular}{|c|c|c|c|c|c|c|c|c|c|}
\hline \multirow{2}{*}{$\begin{array}{l}\text { Patient } \\
\text { No. }\end{array}$} & \multirow{2}{*}{$\begin{array}{l}\text { Sex/age } \\
(\mathrm{yr})\end{array}$} & \multirow[b]{2}{*}{ Injury mechanism } & \multirow{2}{*}{$\begin{array}{l}\text { Duration of } \\
\mathrm{F} / \mathrm{U}(\mathrm{mo})\end{array}$} & \multicolumn{2}{|c|}{ Radial head Fx. } & \multirow{2}{*}{$\begin{array}{l}\text { Coronoid Fx. } \\
\text { (Regan \& Morrey } \\
\text { classification) }\end{array}$} & \multicolumn{2}{|c|}{ Ligament injury } & \multirow[b]{2}{*}{ Complicatior } \\
\hline & & & & $\begin{array}{c}\text { Articular } \\
\text { involvement }\end{array}$ & OP method & & $\begin{array}{c}\text { LCL } \\
\text { complex }\end{array}$ & MCL & \\
\hline 1 & $\mathrm{M} / 31$ & Fall from height & 50 & 0 & Conservative Tx. & II & $\mathrm{O}$ & $\mathrm{X}$ & None \\
\hline 2 & $\mathrm{M} / 55$ & Slip down & 24 & 10 & Partial excision & II & $\mathrm{O}$ & $\mathrm{O}$ & None \\
\hline 3 & $\mathrm{~F} / 57$ & Slip down & 24 & 0 & Conservative Tx. & II & $\mathrm{O}$ & $\mathrm{O}$ & None \\
\hline 4 & $\mathrm{~F} / 61$ & Slip down & 35 & 10 & Partial excision & II & $\mathrm{O}$ & $\mathrm{O}$ & None \\
\hline 5 & $\mathrm{M} / 21$ & Slip down & 29 & 0 & Conservative Tx. & II & $\mathrm{O}$ & $\mathrm{O}$ & Nonunion \\
\hline 6 & $\mathrm{M} / 68$ & Slip down & 30 & 0 & Conservative Tx. & II & $\mathrm{O}$ & $\mathrm{X}$ & None \\
\hline 7 & $\mathrm{M} / 56$ & Fall from height & 24 & 10 & Partial excision & I & $\mathrm{O}$ & $\mathrm{O}$ & None \\
\hline 8 & $\mathrm{M} / 18$ & Fall from height & 26 & 0 & Conservative Tx. & I & $\mathrm{O}$ & $\mathrm{O}$ & None \\
\hline 9 & $\mathrm{M} / 40$ & $\begin{array}{l}\text { Passenger traffic } \\
\text { accident }\end{array}$ & 27 & 20 & Partial excision & II & $\mathrm{O}$ & $\mathrm{O}$ & None \\
\hline 10 & $\mathrm{~F} / 58$ & Slip down & 32 & 25 & Partial excision & II & $\mathrm{O}$ & $\mathrm{X}$ & Nonunion \\
\hline 11 & $\mathrm{M} / 72$ & $\begin{array}{l}\text { Passenger traffic } \\
\text { accident }\end{array}$ & 26 & 20 & Partial excision & II & $\mathrm{O}$ & $\mathrm{O}$ & $\begin{array}{l}\text { Pin site } \\
\text { irritation }\end{array}$ \\
\hline 12 & $\mathrm{~F} / 72$ & Slip down & 24 & 0 & Conservative Tx. & I & $\mathrm{O}$ & $\mathrm{O}$ & None \\
\hline 13 & $\mathrm{M} / 28$ & Slip down & 36 & 30 & Partial excision & II & $\mathrm{O}$ & $\mathrm{X}$ & None \\
\hline 14 & $\mathrm{M} / 22$ & Slip down & 36 & 20 & Partial excision & II & $\mathrm{O}$ & $\mathrm{X}$ & None \\
\hline 15 & $\mathrm{M} / 43$ & Fall from height & 26 & 30 & Partial excision & II & $\mathrm{O}$ & $\mathrm{O}$ & None \\
\hline 16 & $\mathrm{M} / 36$ & $\begin{array}{l}\text { Passenger traffic } \\
\text { accident }\end{array}$ & 27 & 45 & Partial excision & I & $\mathrm{O}$ & $\mathrm{X}$ & None \\
\hline 17 & $\mathrm{M} / 45$ & Fall from height & 24 & 0 & Conservative Tx. & II & $\mathrm{O}$ & $\mathrm{O}$ & Nonunion \\
\hline 18 & $\mathrm{M} / 14$ & Slip down & 24 & 0 & Conservative Tx. & II & $\mathrm{O}$ & $\mathrm{O}$ & None \\
\hline 19 & $\mathrm{M} / 51$ & Fall from height & 24 & 45 & Partial excision & I & $\mathrm{O}$ & $\mathrm{O}$ & None \\
\hline
\end{tabular}

F/U: follow-up, Fx.: fracture, OP: operative, LCL: lateral collateral ligament, MCL: medial collateral ligament, M: male, F: female, Tx: treatment. 
anchor suture on the articular side of the LCL complex footprint of the humeral attachment. ${ }^{11,12)}$ After surgery, the joint was rendered immovable for approximately 2 to 3 days using a splint, which was later replaced with an elbow hinged brace to allow a phased joint movement. Follow-up consultations were conducted at 6 weeks and at 3, 6, 12, and 24 months after surgery.

\section{Clinical Evaluation \& Statistical Analysis}

The range of motion (ROM), visual analogue scale (VAS) score, Mayo elbow performance score (MEPS), surgical complications, radiological outcomes (e.g., heterotopic ossification, varus or valgus deformity, and radiocapitellar and ulnohumeral arthrosis), and postoperative complications were evaluated at the follow-up.

Statistical analysis was conducted using PASW for Windows, ver. 18.0 (IBM Co., Armonk, NY, USA). Mann-Whitney U-test was used to assess the significance of differences (with 95\% confidence intervals) in the ranges of motion of the elbow joints, VAS and MEPS between groups at final follow-up.

\section{Results}

Initially, 23 patients who underwent all-arthroscopic management for elbow fracture-dislocation were identified and enrolled. Of these, 4 patients with ORIF were excluded, and 19 patients ( 15 males; 4 females) with a mean age of 44.6 years (range, 14-72 years, at the time of injury) were finally included in the analysis. The mean follow-up period was 28.8 months (range, 24-50 months).

Radial head fractures were treated via arthroscopic partial excision in 11 patients (Group A) and non-excision in 8 patients (Group B). According to arthroscopic findings, all patients had $\mathrm{LCL}$ complex rupture and coronoid process fracture (or anterior capsular avulsion). Combined coronoid fracture and $\mathrm{LCL}$ complex injury were treated using an arthroscopic technique for restoring the elbow stability in all cases. Analyzing the collateral ligaments revealed 13 cases (68.4\%) of medial collateral injury and 19 cases $(100 \%)$ of lateral collateral injury. In all patients with medial and LCL injuries, stability was obtained only via arthroscopic LCL repair. No patient required medial collateral ligament repair or the application of a dynamic external fixator. The patient characteristics, comorbidities, and mechanisms of injury are described in Table 1.

Comparison of differences between the partial radial head excision group (Group A) and non-excision group (Group B) analyzed by the Mann-Whitney U-test showed no significant difference between the variables of age, length of follow-up, MEPS, ROM (flexion, extension, supination, and pronation), and associated arcs of motion (Table 2).

At the final follow-up, all 19 patients showed complete resolution of their elbow instability, and a negative outcome for the varus stress test and pivot-shift test. The mean flexion contracture angle was $5.0^{\circ}$ (range, $0^{\circ}-20^{\circ}$ ); further flexion angle, $135.8^{\circ}$ (range, $120^{\circ}-150^{\circ}$ ); supination angle, $77.4^{\circ}$ (range, $60^{\circ}-80^{\circ}$ ); and pronation angle, $71.6^{\circ}$ (range, $50^{\circ}-70^{\circ}$ ). The clinical score was satisfactory, with mean MEPS of 92.9 (range, 70-100). Based on this validated outcome score, the elbow performance was rated as excellent for 11 patients, good for 7 patients, and fair for 1 patient.

No complications involving blood vessels or nerves were observed in both groups. However, there was 1 case of pin-site irritation, which was a complication of arthroscopic fixation of coronoid fractures; it resolved completely after removal of the pin. Radiological findings showed no problems related to complications of the radiocapitellar joint. However, non-union of coracoid fractures was observed in 3 patients ( 1 in Group A and 2 in Group B) without any accompanying instability and clinical symptoms.

\section{Discussion}

Our data indicate that arthroscopic partial excision is a viable treatment option for comminuted fractures with elbow dislocation. According to our results, the rate of good clinical outcomes

Table 2. Comparison of Clinical Outcomes between the Two Groups

\begin{tabular}{|c|c|c|}
\hline Variable & $\begin{array}{l}\text { Partial excision group } \\
\qquad(\mathrm{n}=11)\end{array}$ & $\begin{array}{l}\text { Non-excision group } \\
\qquad(\mathrm{n}=8)\end{array}$ \\
\hline \multicolumn{3}{|l|}{ Sex } \\
\hline Male & 9 & 6 \\
\hline Female & 2 & 2 \\
\hline Age (yr) & $44.6(22-72)$ & $47.5(14-72)$ \\
\hline Follow-up (mo) & $28.8(24-36)$ & $28.8(24-50)$ \\
\hline \multicolumn{3}{|l|}{ Injury side } \\
\hline Right & 9 & 4 \\
\hline Left & 2 & 4 \\
\hline VAS & 1.4 & 1.5 \\
\hline MEPS (max, 100) & $93.2(85-100)$ & $92.5(70-100)$ \\
\hline \multicolumn{3}{|l|}{ Range of motion $\left(^{\circ}\right)$} \\
\hline $\mathrm{FC}$ & $8.18(0-20)$ & $7.50(0-10)$ \\
\hline $\mathrm{FF}$ & $134.6(120-150)$ & $127.5(120-140)$ \\
\hline $\mathrm{FC} / \mathrm{FF}$ arc & $126.5(110-150)$ & $120.0(110-140)$ \\
\hline Sup & $63.6(60-80)$ & $70.0(60-80)$ \\
\hline Pro & $60.0(50-70)$ & $60.0(50-70)$ \\
\hline Sup/Pro arc & 123.6 & 130.0 \\
\hline
\end{tabular}

Values are presented as number only or median (range).

VAS: visual analogue scale, MEPS: Mayo elbow performance score, FC: flexion contracture, FF: further flexion, Sup: supination, Pro: pronation. 
and patient satisfaction in the arthroscopic partial excision group is similar to that in the non-excision group, which has fewer injuries and a low complication rate when internal fixation was difficult owing to severe comminuted fracture of the radial head. We believe that if elbow joint stability is achieved even after removal of half the radial head articular surface, the remnant joint can exhibit satisfactory clinical results without severe complications. In this study, the indication of radial head partial excision is comminuted fractures involving $<50 \%$ of the articular surface which cannot be reduced, and we achieved elbow joint stability through coronoid process fixation and LCL complex repair. Results of this study support our hypothesis and indication.

The desired clinical outcome for radial head fractures with elbow fracture-dislocation is the restoration of elbow joint stability and allowance of early active motion to avoid the stiffness, rather than absolute reduction and stabilization of the fractured bony structure, as seen in isolated radial head fractures. ${ }^{13)}$ In this respect, the excision of a severely comminuted non-reconstructable fragment, as a mechanical block, can provide early active elbow motion and reduce the potential of stiffness. Historically, several authors have advocated radial head excision in cases of displaced and comminuted fractures that cannot be adequately treated with open reduction and internal fixation, with acceptable clinical outcomes being reported in long-term followups. $^{10,14)}$

In contrast, recent studies stress the role of the radial head in maintaining elbow and the forearm stability. Hence, to preserve the physiological elbow and forearm kinematics, some authors suggest performing an open reduction and internal fixation or a prosthetic replacement of the radial head in cases of displaced or comminuted fractures. ${ }^{15-17)}$ However, if satisfactory reduction cannot be achieved in cases of severely comminuted fractures, resection of the radial head would be the treatment of choice, and is eventually associated with radial head replacement. ${ }^{4,18)}$ Occasionally, open procedures for elbow fracture-dislocation are challenging, in that exposure to certain parts may destabilize the elbow or put neurovascular structures at risk. Furthermore, stiffness is a frequent complication, ranging from capsular fibrosis to heterotopic ossification. To avoid these complications, the arthroscopic approach has emerged as a safe and effective means for a wide range of acute and chronic elbow pathologies. Some studies report several advantages of arthroscopic management of elbow fractures, including improved visualization, better wound healing, preservation of soft tissue, and opportunity for early motion, thereby minimizing complications resulting from stiffness. ${ }^{11,12,19,20)}$ The most important advantage of arthroscopic management over open procedures is that it offers an appropriate view of the articular surface without damaging the surrounding soft tissue. ${ }^{21)}$ Other advantages include better evaluation and resolution of associated lesions such as loose bodies, osteophytes, and injured cartilage debris. Minimal additional tissue damage with early mobilization as well as the prevention of hemarthrosis and removal of articular debris decreases the risk of adherences and creates circumstances allowing for a better functional outcome. ${ }^{22,23)}$ In the current study, we observed no cases of neurovascular damage and fluid extravasation. However, since the possibility of neurovascular damage and irrigation fluid extravasation exists, knowledge of elbow anatomy and skilled arthroscopic techniques is essential for successful management.

Until recently, studies focusing on the arthroscopic management of acute elbow injury have been widely published, and there is insufficient evidence supporting arthroscopic management of comminuted radial head fractures with elbow fracturedislocation. To date, very few studies have evaluated the clinical outcomes of arthroscopic excision of radial head fracture with elbow fracture-dislocation. We propose the indication and possibility for arthroscopic radial head excision in elbow fracturedislocation, and therefore believe our research to be significant.

The first limitation of this study is the relatively short-term follow-up duration and the retrospective nature of data collection and analysis which could introduce patient selection bias (age, gender, functional demand) and the potential for confounding. Although no degenerative changes were found in the radiocapitellar joint in our 2-year follow-up, we cannot eliminate the possibility of an excised radial head causing arthritic changes. Future long-term studies are required to warrant any significant changes in the treatment of comminuted radial head fractures. Furthermore, for arthroscopic radial head partial excision to be an accepted treatment option, it is necessary to ensure joint stability as a precondition by arthroscopic coronoid fracture fixation and LCL complex repair. These procedures are technically challenging with a steep learning curve. However, despite this limitation, it is important to note that arthroscopic techniques have superseded open techniques for many orthopedic conditions, other than those of the elbow. This is because of the minimally invasive nature of arthroscopic procedures and their ability to decrease the surgical time and surgical site morbidity.

The current study analysis does not propose that arthroscopic partial excision for radial head fracture with elbow dislocation should replace any existing accepted treatment; however, we suggest that if the indications are met, this method should be considered an effective and acceptable treatment option for elbow fracture-dislocation.

\section{Conclusion}

If accompanied by coronoid fracture fixation and LCL complex repair for restoring elbow stability, arthroscopic partial excision for radial head comminuted fractures involving $<50 \%$ of articular surface should be considered an effective and acceptable treatment option for elbow fracture-dislocation. 


\section{References}

1. Morrey BF, Chao EY, Hui FC. Biomechanical study of the elbow following excision of the radial head. J Bone Joint Surg Am. 1979;61(1):63-8.

2. Johnston GW. A follow-up of one hundred cases of fracture of the head of the radius with a review of the literature. Ulster Med J. 1962;31:51-6.

3. Pike JM, Athwal GS, Faber KJ, King GJ. Radial head fractures: an update. J Hand Surg Am. 2009;34(3):557-65.

4. Ring D. Displaced, unstable fractures of the radial head: fixation vs. replacement: what is the evidence? Injury. 2008; 39(12):1329-37.

5. Tejwani NC, Mehta $\mathrm{H}$. Fractures of the radial head and neck: current concepts in management. J Am Acad Orthop Surg. 2007;15(7):380-7.

6. Ring D, Jupiter JB, Zilberfarb J. Posterior dislocation of the elbow with fractures of the radial head and coronoid. J Bone Joint Surg Am. 2002;84(4):547-51.

7. An KN, Morrey BF. Biomechanics of the elbow. In: Morrey BF, ed. The elbow and its disorders. Philadelphia: WB Saunders Co; 1993. 43-61.

8. Radin EL, Riseborough EJ. Fractures of the radial head. A review of eighty-eight cases and analysis of the indications for excision of the radial head and non-operative treatment. J Bone Joint Surg Am. 1966;48(6):1055-64.

9. Faldini C, Nanni M, Leonetti D, et al. Early radial head excision for displaced and comminuted radial head fractures: considerations and concerns at long-term follow-up. J Orthop Trauma. 2012;26(4):236-40.

10. Wijeratna M, Bailey KA, Pace A, Tytherleigh-Strong G, Van Rensburg L, Kent M. Arthroscopic radial head excision in managing elbow trauma. Int Orthop. 2012;36(12):2507-12.

11. Lee JM, Yi Y, Kim JW. Arthroscopically assisted surgery for coronoid fractures. Orthopedics. 2015;38(12):742-6.
12. Kim JW, Yi Y, Kim TK, et al. Arthroscopic lateral collateral ligament repair. J Bone Joint Surg Am. 2016;98(15):1268-76.

13. Pierrart J, Bégué T, Mansat P; GEEC. Terrible triad of the elbow: treatment protocol and outcome in a series of eighteen cases. Injury. 2015;46 Suppl 1:S8-12.

14. Herbertsson P, Hasserius R, Josefsson PO, et al. Mason type IV fractures of the elbow: a 14- to 46-year follow-up study. J Bone Joint Surg Br. 2009;91(11):1499-504.

15. Beingessner DM, Dunning CE, Gordon KD, Johnson JA, King G). The effect of radial head excision and arthroplasty on elbow kinematics and stability. J Bone Joint Surg Am. 2004; 86(8):1730-9

16. Charalambous CP, Stanley JK, Siddique I, Powell E, Ramamurthy C, Gagey O. Radial head fracture in the medial collateral ligament deficient elbow; biomechanical comparison of fixation, replacement and excision in human cadavers. Injury. 2006;37(9):849-53.

17. Jensen SL, Olsen BS, Søjbjerg JO. Elbow joint kinematics after excision of the radial head. J Shoulder Elbow Surg. 1999;8(3):238-41.

18. King GJW. Management of radial head fractures with implant arthroplasty. J Am Soc Surg Hand. 2004;4(1):11-26.

19. Fink Barnes LA, Parsons BO, Hausman M. Arthroscopic management of elbow fractures. Hand Clin. 2015;31(4):651-61.

20. Michels F, Pouliart N, Handelberg F. Arthroscopic management of Mason type 2 radial head fractures. Knee Surg Sports Traumatol Arthrosc. 2007;15(10):1244-50.

21. Menth-Chiari WA, Poehling GG, Ruch DS. Arthroscopic resection of the radial head. Arthroscopy. 1999;15(2):226-30.

22. Hardy P, Menguy F, Guillot S. Arthroscopic treatment of capitellum fracture of the humerus. Arthroscopy. 2002;18(4):4226.

23. Rolla PR, Surace MF, Bini A, Pilato G. Arthroscopic treatment of fractures of the radial head. Arthroscopy. 2006;22(2):233. e1-6. 